\title{
CHARACTERISTIC OF AMELOBLASTOMA IN ORAL AND MAXILLOFACIAL SURGERY AT HASAN SADIKIN HOSPITAL : 2 YEARS RETROSPECTIVE STUDY
}

\author{
Albertin Jane Agung Tanusantoso*, Harmas Yazid Yusuf**, Melita Sylvyana*** \\ ${ }^{\star}$ Resident, Department of Oral and Maxillofacial Surgery, RSUP Dr. Hasan Sadikin, Faculty of Dentistry, \\ Padjadjaran University \\ ** Department of Oral and Maxillofacial Surgery, Faculty of Dentistry, Padjadjaran University \\ **Department of Oral and Maxillofacial Surgery, RSUP Dr. Hasan Sadikin, Padjadjaran University \\ Correspondence: albertin18001@mail.unpad.ac.id
}

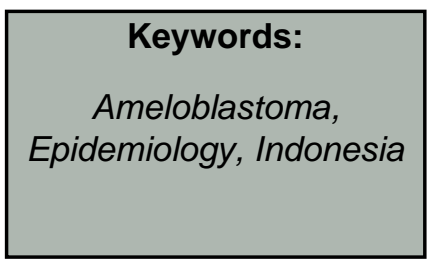

\begin{abstract}
Background: Ameloblastoma is the most common odontogenic tumor. Ameloblastoma is a borderline tumor because it is a benign but locally aggressive tumor with a high recurrence rate if the excision is not complete. The principle of treatment for ameloblastoma is excision all the tumor. This article aimed to conduct a retrospective study to analyze the characteristics of ameloblastoma in patients at Oral and Maxillofacial Surgery Hasan Sadikin Hospital Oral Surgery between the period of January 2018-December 2019

Method: This is a retrospective study with 37 patients diagnosed with ameloblastoma during 2018-2019. We took data from each patient such as gender, age, radiological features, histopathological diagnosis of the location of ameloblastoma, management, defects, reconstruction.

Result: A total of 22 patients were diagnosed with plexiform ameloblastoma, 12 cases of follicular ameloblastoma, 3 cases of mixed plexiform and follicular ameloblastoma. 31 patients were treated radically, while 6 patients were treated conservatively. Radical treatment is more often used to reduce recurrence rates, whereas conservative measures are indicated in children and adolescents, as well as adult patients with unilocular ameloblastoma types.

Conclusion: The most characteristic of ameloblastoma is plexiform ameloblastoma in the mandible. Ameloblastoma is usually performed radically and reconstructed with an $A O$ plate.
\end{abstract}

\section{INTRODUCTION}

Ameloblastoma is the most common odontogenic tumor, based on previous research showed that ameloblastoma occurred in $49 \%$ of odontogenic tumors. Based on its nature, ameloblastoma is an intermediate (borderline) tumor because it is benign but locally invasive with a high recurrence rate if the excision is not perfect. ${ }^{1,2,3,4}$

There was a study that showed the number of ameloblastoma was significantly higher in Asian or African hospitals compared to European or
American hospitals. Chinese population showed a mean age of 31.4 years with a ratio of $1.5: 1$ male: female and $90.8 \%$ of the tumors were in the mandible, while Japanese population showed a mean age of 34.7 years with a ratio of 1.6:1 male: female and $92.6 \%$ was located in the mandible. ${ }^{2,4,5,6}$ Out of 84 patients diagnosed with ameloblastoma, 14 patients were diagnosed with unicystic ameloblastoma (25\%), thirty-two patients with follicular ameloblastoma (57\%) and 10 patients with multicystic ameloblastoma (18\%). The principle of therapy for ameloblastoma of the jaw is 
the removal of the entire tumor. Many clinicians prefer radical therapy because of the relapsing nature of the disease. Treatment with radical methods can reduce the recurrence rate..$^{4,5}$

This tumor has a high recurrence rate, therefore, close evaluation and observation after treatment are needed. Hasan Sadikin Hospital (RSHS) is a referral centre at the West Java Province and there had been no research on the characteristics of ameloblastoma that occurred in the West Java area, especially at Hasan Sadikin Hospital. Based on the problem presented, this study aimed to conduct a retrospective study analyzing the characteristics of ameloblastoma in patients at RSHS Oral Surgery KSM between the period of January 2018 until December 2019.

\section{MATERIALS AND METHODS}

This study's ethical exemption was approved by research ethics committee Universitas Padjadjaran with number of 598/UN6.KEP/EC/2020. The samples of this study were all patients who were diagnosed with ameloblastoma radiologically and histopathologically at the KSM Oral and Maxillofacial Surgery of RSHS between the period of January 2018 to December 2019. Data of each patient was collected, including age, gender, clinical diagnosis, histopathological diagnosis, management and rehabilitation.

The age category in this study was the age at which the patients were diagnosed with ameloblastoma. They were grouped into 5 age groups: 0-10 year-old; $11-20$ year-old; $21-30$ yearold; 41-50 year-old and over 50 year-old. Gender was divided into male and female. Based on radiographic examination by reading both panoramic images and head CT scans, ameloblastoma is classified into 3 types: unilocular, multilocular (soap bubble appearance) and desmoplastic (scallop appearance).7, 8,9,10,11

Based on histopathological examination, ameloblastoma is grouped into 6 types: unilocular, plexiform, follicular, acanthomatous, granular, basal cell and desmoplastic. The locations of ameloblastoma are grouped into 6 locations: anterior maxilla, right maxilla, left maxilla, anterior mandible, right mandible and left mandible. 12,13,14,15

Management of ameloblastoma is generally divided into 2 types: conservative and radical. There are two types of conservative management, enucleation and dredging, whereas radical management includes marginal resection, segmental resection, hemimandibulectomy/ hemimaxillectomy, and total mandibulectomy/ maxillectomy. ${ }^{16,17,18,19,20}$

Assessment of the extent of maxillary defects after ameloblastoma treatment based on the classification system for maxillectomy defect (Figure 1) is divided into two. Limited maxillectomy defects covers one or two maxillary walls accompanied by buccal soft tissue covering the maxilla or critical structures such as the lips, nose and eyelids. Subtotal maxillectomy defects includes the palate, leaving dentoalveolar and orbital walls intact. Subtotal maxillectomy defects are divided into 2 types, type IIA and IIB. Type IIA defect involves less than $50 \%$ of the maxilla and does not cross the midline, whereas type IIB involves more than $50 \%$ of the maxilla and crosses the midline. Total maxillectomy defects involve the orbital floor, dentoalveolar, and may be accompanied by orbital resection. This defect is divided into 2 types, type IIIA and type IIIB. Type IIIA defect involves the entire maxillary wall including the orbital floor but leaves the internal structures of the orbit. Type IIIB involves the entire maxillary wall including the internal structures of the orbit. Orbito maxillectomy 
defect involves the entire maxillary structure, superior orbital wall and inner orbital structures. ${ }^{21,22}$

Classification of mandibular defects with roman numerals (I, II, and III) indicates defects in bones, while letters $(A, B, C, D)$ indicates soft tissue quality (Figure 2). Type I involves the anterior arch of the mandible (mandibular symphysis and/or parasymphysis either unilateral or bilateral). Type II involves half of the mandible (body, angle, ramus, with or without condyles). Type III involves a lateral defect involving one or two or three parts of the mandibular structure (body, angle, ramus). Type A shows no soft tissue defects. Type $B$ involves intraoral soft tissue. Type $C$ shows defect in the skin or extra-oral soft tissue. Type D defect occurs in either intraoral or extra-oral soft tissue. ${ }^{22}$

\section{RESULT}

The data collected on the characteristics of ameloblastoma in patients at KSM Oral and Maxillofacial Surgery of RSHS in the period between January 2018 to December 2019 showed 37 patients received treatment. The data showed 11 (29.73\%) male patients and $26(70.27 \%)$ female patients (Figure 3 ). The majority of ameloblastoma patients were of age 41-50 years and over 50 years with $8(21.62 \%)$ patients respectively, while 1 (2.7\%) patient was at the age of $0-10$ years (Figure $4)$.

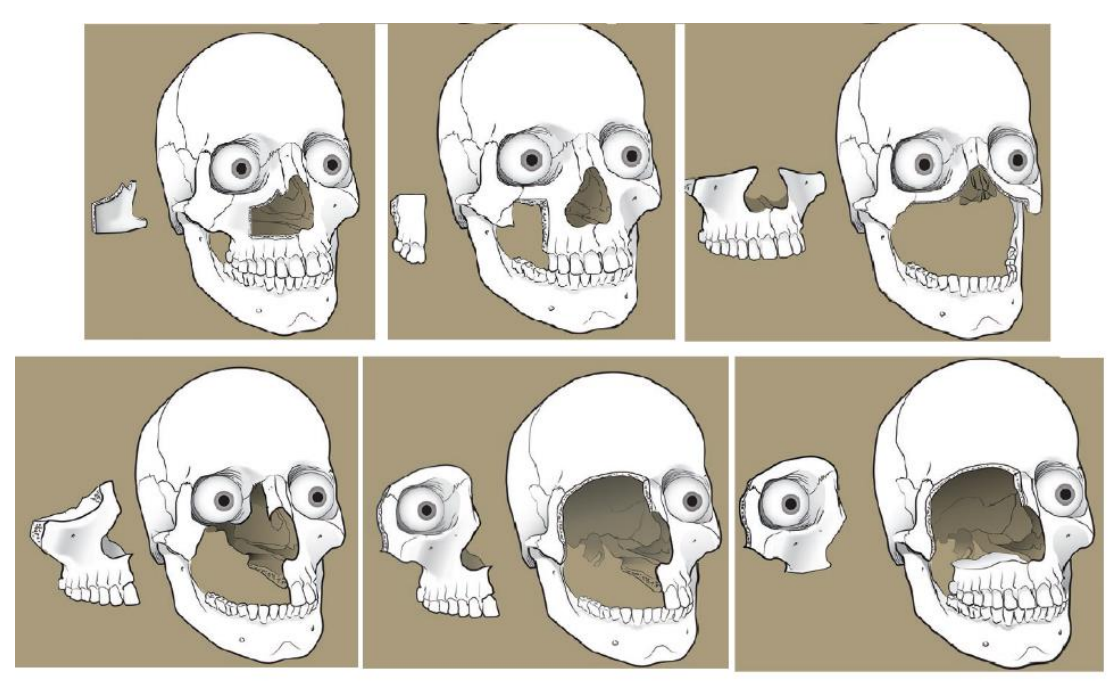

Figure 1. Classification of Maxillectomy Defects; 7a. Type I. Limited Maxillary Defects; 7b. Type IIA. Subtotal Maxillectomy Defects; 7c. Type IIB Subtotal Maxillectomy Defects; 7d. Type IIIA Total Maxillectomy Defects without involving orbital; 7e. Type IIIB Total Maxillectomy Defects involving orbital; 7f. Type IV Orbitomaxillary Defects $^{22}$ 


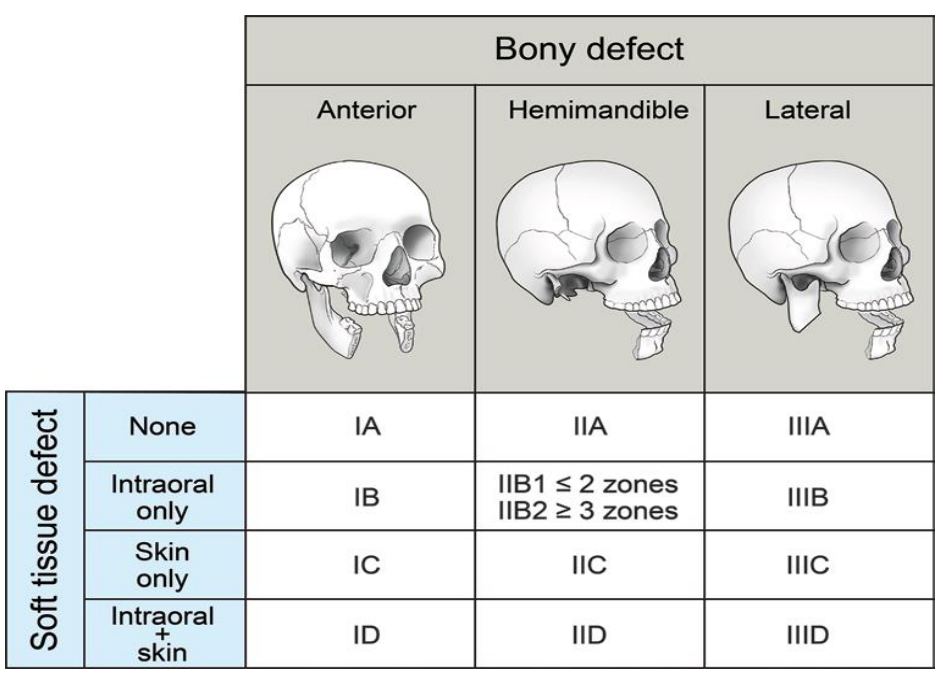

Figure 2. Classification of Mandibulectomy Defects ${ }^{22}$

Based on the radiographic examination, 11 (29.73\%) patients were diagnosed with unicystic ameloblastoma, 21 (56.76\%) patients were multicystic and 5 (13.51\%) patients were desmoplastic (Figure 5). Histopathological examination revealed plexiform ameloblastoma on 22 (59.46\%) patients, follicular on 12 (32.43\%) patients, mixed plexiform and follicular in $3(8.11 \%)$ patients (Figure 6).

Based on the location, maxilla was involved in 3 patients and mandible was involved in 34 patients. Anterior maxilla, right maxilla and left maxilla were each involved in 1 (1.7\%) patient, whereas in mandible the majority of the location was on the left mandible consisting of 19 (51.35\%) patients, while the right mandible was involved in 12 (32.43\%) patients; anterior was involved in $1(2.7 \%)$ patient; and both right and left involvement occurred in 2 (5.41\%) patients (Figure 7).

Figure 8 shows that management for ameloblastoma was divided into conservative and radical management, where conservative management of ameloblastoma with enucleation was given to 1 patient $(2.7 \%)$ and the dredging method was given to 5 patients (13.51\%). Radical management that was performed was segmental resection in 14 patients (13.84\%), hemimaxillectomy in 2 patients $(5.41 \%)$, and hemimandibulectomy in 15 patients (40.54\%).

Figures 9 and 10 show defects in the maxilla and mandible in the case of maxillary ameloblastoma, involving one or two walls of the maxilla and involving $<50 \%$ of the maxilla ( 1 patient), not passing through the midline (1 patient) and leaving no defect (1 patient). Whereas in mandible, most defects involved half of the mandible and were also found extraoral and intraoral defects (10 patients). Regarding the reconstruction and rehabilitation measures, 24 patients $(64.86 \%)$ were subjected to $\mathrm{AO}$ plate placement, 4 patients $(10.81 \%)$ had grafts taken from the ribs, and 9 patients (24.32\%) were subjected to prostheses (Figure 11). 


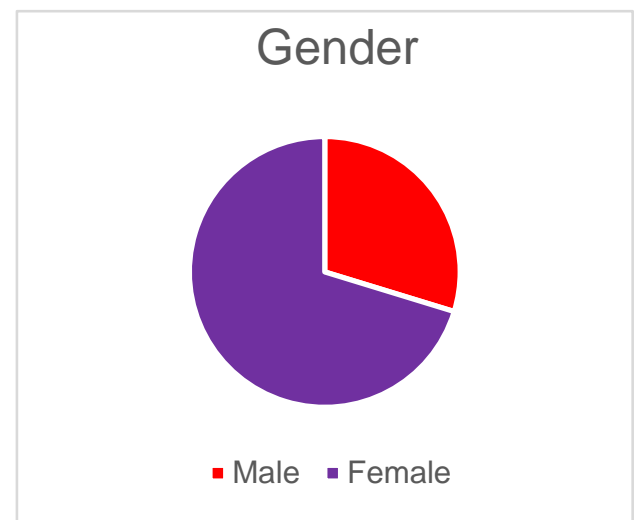

Figure 3. Gender Distribution of Ameloblastoma

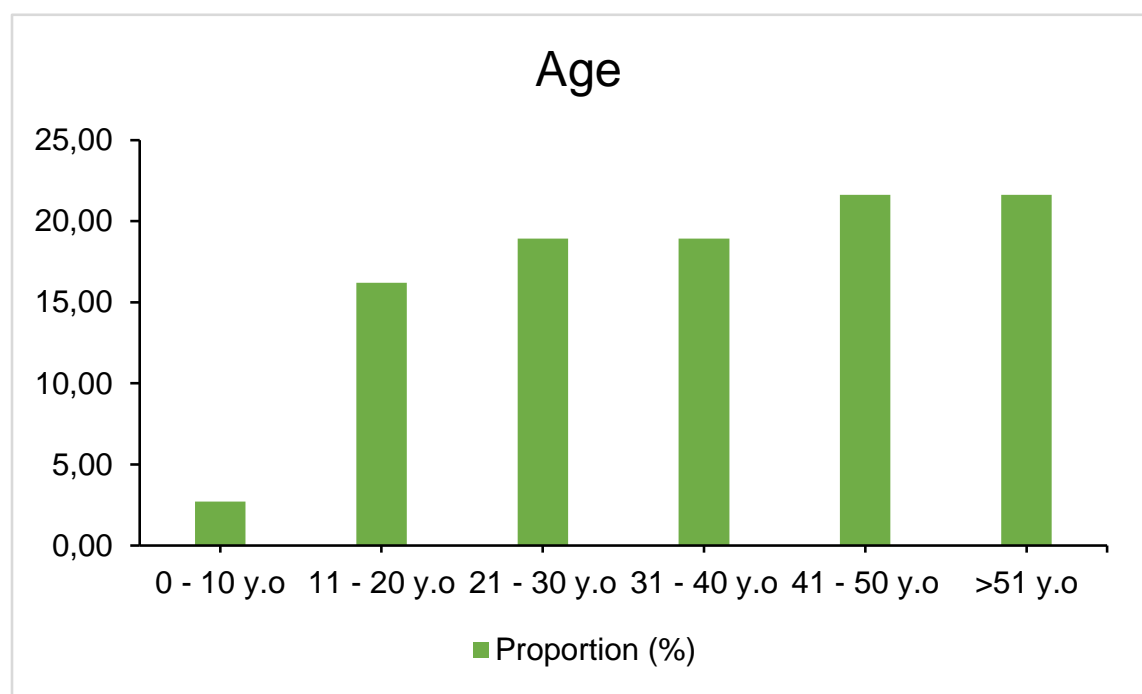

Figure 4. Age Distribution of Ameloblastoma

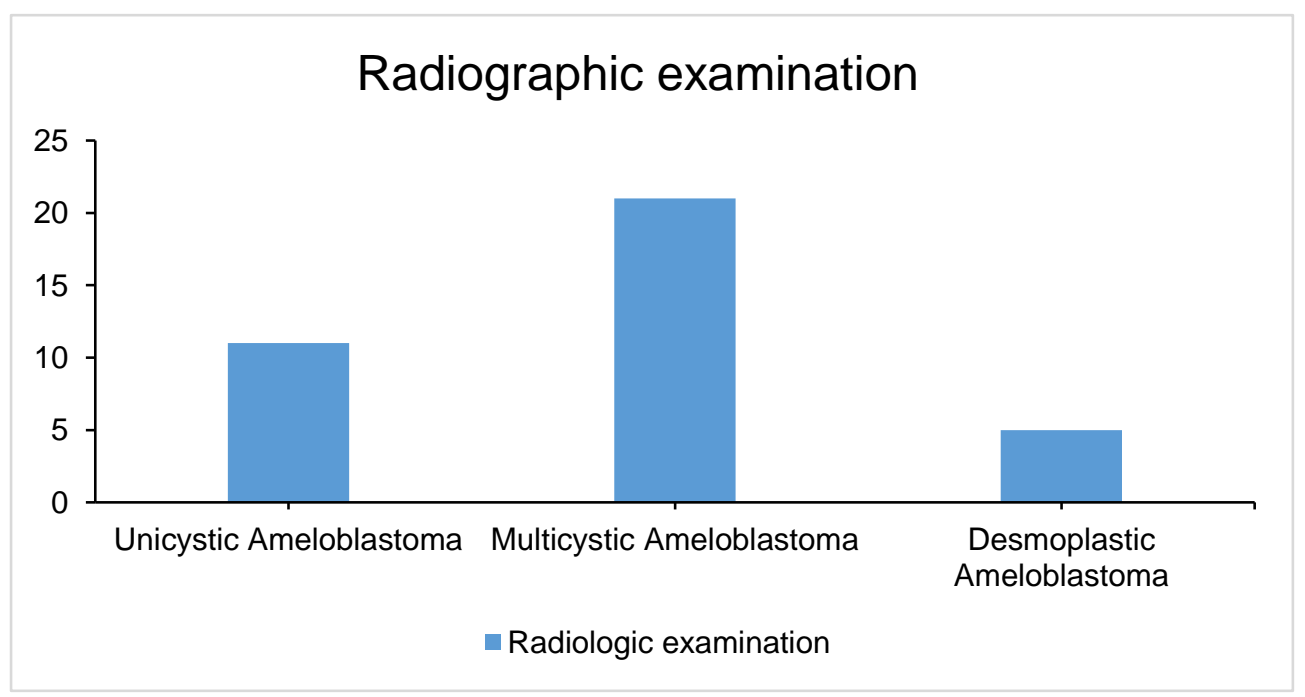

Figure 5. Radiographic Examination 


\section{Histopathological examination}

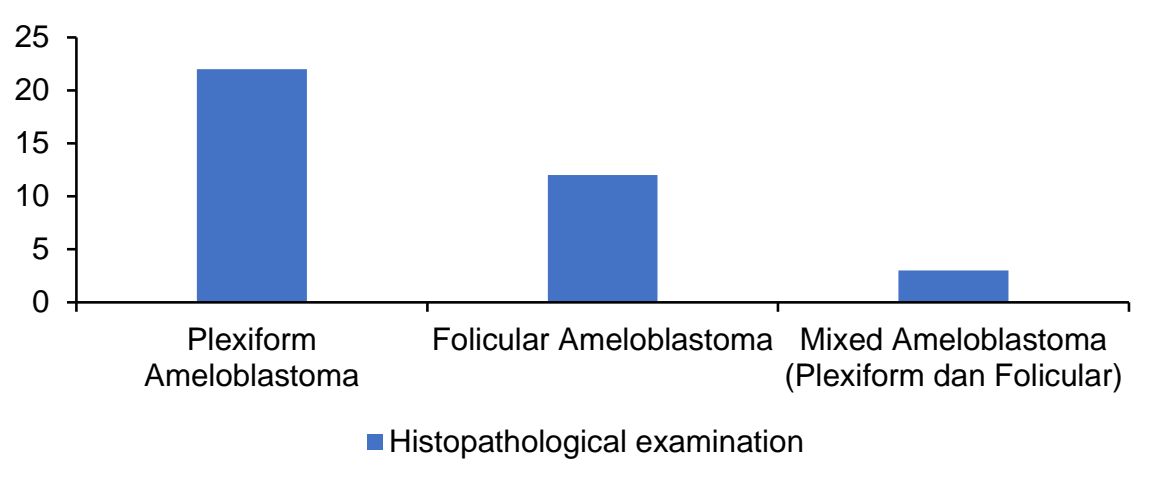

Figure 6. HIstopathological Examination

\section{Location}

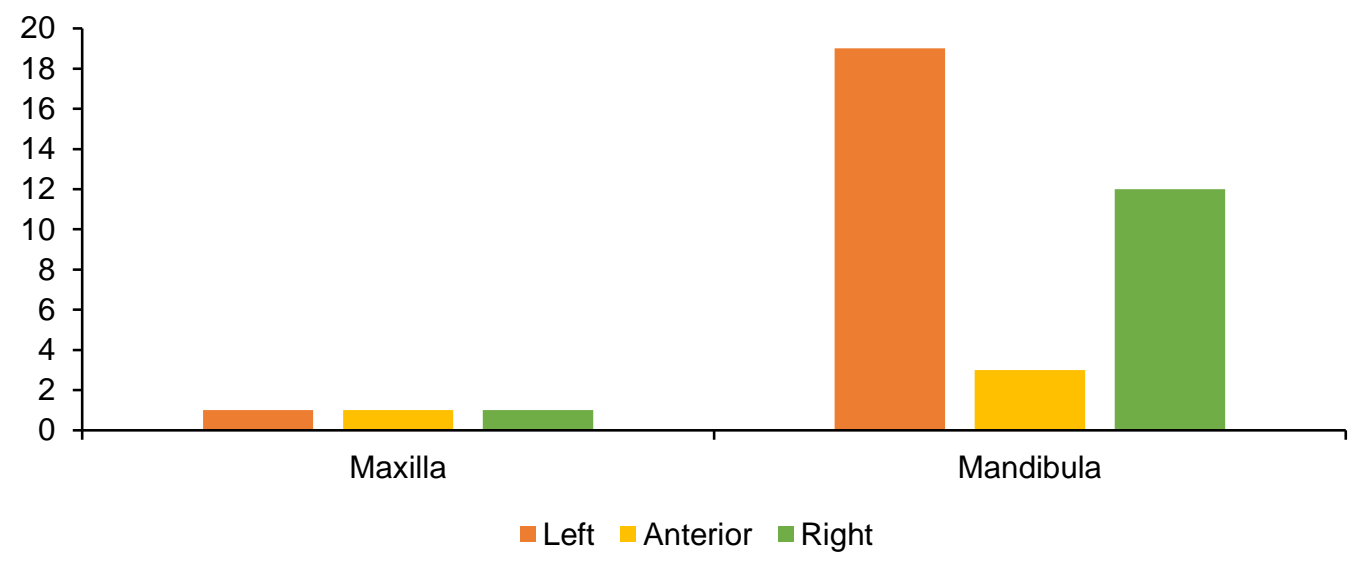

Figure 7. Location Predilection of Ameloblastoma

\section{Treatment of Ameloblastoma}

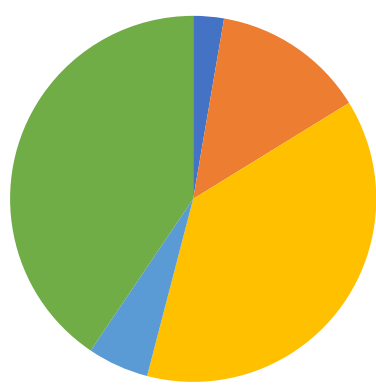

$$
\begin{array}{ll}
\square \text { Enucleation } & \text { Dredging } \\
\square \text { Marginal Resection } & \text { Segmental Resection } \\
\square \text { Maxillectomy } & \quad \text { Hemimandibulectomy }
\end{array}
$$

Figure 8. Treatment of Ameloblastoma 


\section{Maxillectomy Defects}

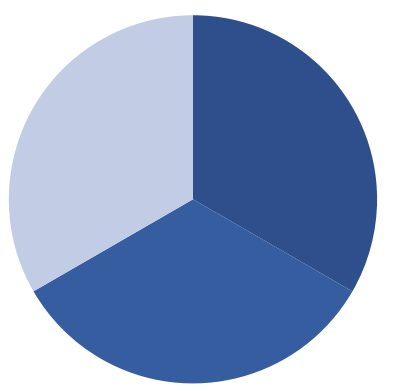

-Type I $\quad$ Type II A $\quad$ Type II B $\quad$ Type III A

-Type III B $\square$ Type IV $\quad$ Unidentified

Figure 9. Maxillectomy Defects

\section{Mandibulectomy Defects}

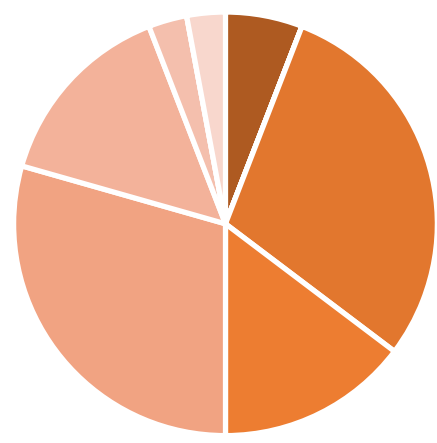

- Type IA - Type IB - Type IC - Type ID - Type IIA

- Type IIB (1) $=$ Type IIB (2) - Type IIC $\quad$ Type IID $\quad$ Type IIIA

- Type IIIB $\quad$ Type IIIC $\quad$ Tipe IIID

Figure 10. Mandibulectomy Defects

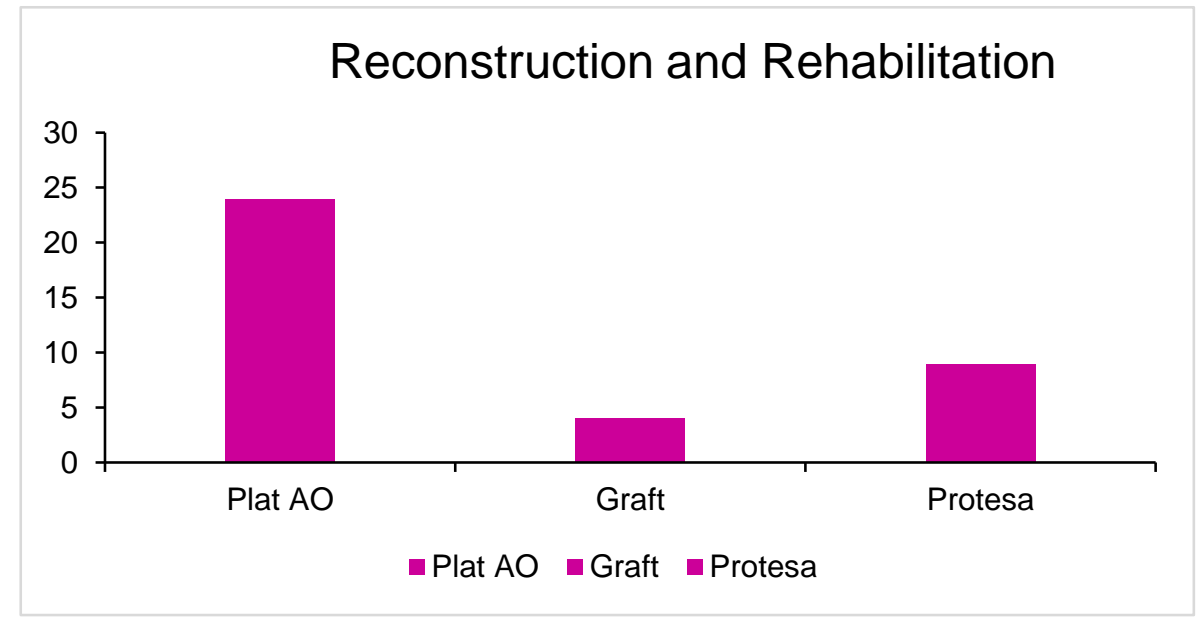

Figure 11. Reconstruction and Rehabilitation 


\section{DISCUSSION}

Ameloblastoma is a benign tumor that grows slowly but is locally invasive, painless and may destroy the bone. The characteristics of ameloblastoma based on radiographic examination and anatomical pathology are very diverse, and analysis is needed to determine the characteristics that often occur in patients at KSM Oral and Maxillofacial Surgery of RSHS. Based on the results of data collection, the incidence of ameloblastoma along with the treatment performed at RSHS from January 2018 to December 2019 recorded 37 patients, with an average age of 37 years. Based on the previous research, average age distribution of ameloblastoma patients in the community in Makassar, Indonesia was 39,7 year-old. This supports the theory that the incidence of ameloblastoma is highest in the third to fourth decade. ${ }^{4}$ Ameloblastoma in a population is more common in women than men. Based on primary data that has been obtained in patients diagnosed with ameloblastoma, from a total of 37 patients, 11 patients were men (29.73\%) and 26 were women (70.27\%).

Aside from radiography, a test to diagnose ameloblastoma is anatomical pathology. This examination showed that the most common type of ameloblastoma cases treated at RSHS between January 2018 to December 2019 was plexiform ameloblastoma with 22 cases, followed by follicular ameloblastoma with 12 cases. Another 3 cases were mixed type ameloblastoma, which is a combination of plexiform and follicular ameloblastoma. A research in 2011 stated that the distribution of ameloblastoma in Cipto Mangunkusumo Public Hospital was 11 cases of follicular ameloblastoma, followed by 6 cases of ameloblastoma. ${ }^{4}$

Treatment for ameloblastoma can be grouped into conservative treatment and radical treatment.
According to previous study, the most chosen treatment action is a radical treatment where the recurrence rate is only $15 \%$ compared to conservative treatment, which is more than $50 \%$. Based on the data that has been obtained at KSM Oral and Maxillofacial Surgery of RSHS, the most frequently performed procedure was hemimandibulectomy in 15 cases, followed by segmental resection in 14 cases, and hemimaxillectomy in 2 cases. Conservative measures performed at KSM Oral and Maxillofacial Surgery of RSHS were dredging in 5 cases and enucleation in 1 case. Radical surgery is more often performed in RSHS because the purpose was to reduce the recurrence rate of ameloblastoma cases, whereas conservative measures were indicated for pediatric and adolescent patients, as well as adult patients with unilocular type of ameloblastoma.

In 2017, WHO classified ameloblastoma into 4 groups, conventional ameloblastoma, unicystic ameloblastoma, extraosseous/peripheral ameloblastoma, and metastazing/malignant ameloblastoma. Each of these types were divided further histologically, conventional ameloblastoma was divided to acanthomatous, basaloid, desmoplastic, follicular, granular cell and plexiform; unicystic ameloblastoma into luminal, intraluminal and mural; extraosseous/peripheral and malignant type were same as conventional ameloblastoma histologically. The odonto-ameloblastoma has been removed from the new classification because of a lack of evidence that it represents a true mixed neoplasm of odontogenic epithelium and mesenchymal tissues. Metastasizing ameloblastoma has also been moved from the section on ameloblastic carcinomas to a type of benign conventional ameloblastoma. It is now clearly defined as a histologically benign typical 
ameloblastoma which metastasizes to distant sites. $^{25}$

The defects that often occur in cases found in RSHS are mostly mandibular, which leads to extraoral and intra-oral defects, consisting of a total of $27.03 \%$ of all cases of ameloblastoma in KSM Oral and Maxillofacial Surgery of RSHS. According to the previous research in India, it shows that the majority of the defects were found in the mandibles, consisting of more than $50 \%$ in Indian population, and another study of stated that ameloblastoma cases were more common and caused mandible defects by $80 \%$. Based on these data, mandible defects could be attributed to ameloblastoma. ${ }^{26}$

AO plate placement, graft placement, and prosthesis construction was performed in these cases at KSM Oral and Maxillofacial Surgery of RSHS. Most reconstruction were carried out by $A O$ plates placement in 24 cases, prosthesis construnction in 9 cases, and graft placement in 4 cases. Selection of reconstruction was based on indication and the extent of surgery defects. ${ }^{2,3}$

\section{CONCLUSION}

Based on this research on the ameloblastoma characteristics distribution at KSM Oral and Maxillofacial Surgery of RSHS between January 2018 to December 2019, it was found that ameloblastoma in female patients was more frequent than in men, and occurred more often in the mandible than in the maxilla. Based on radiological examination, the multicystic type is the most common type followed by unicystic and desmoplastic. Most of the types of ameloblastoma was plexiform form histopathologically. The treatment that was most performed was radical surgery such as segmental resection, total mandibulectomy, and total maxillectomy.

The majority of the defects occur in the mandible, involving extraoral and intraoral tissue.
Good reconstruction treatment for the defects was the placement of $\mathrm{AO}$ plate, construction of prostheses, and grafting which function was to restore the masticatory and esthetics function of the patient.

\section{REFERENCE}

1. Nalabolu GRK, Mohiddin A, Hiremath SKS, et al. Epidemiological Study of Odontogenic Tumors : An Institutional Experience. Journal of Infection and Public Health.2017; $10: 324$ - 330

2. Andersson L, Khanberg KE, Pogrel MA. Oral and Maxillofacial Surgery. 2010. ed-1; 32:629-728. United Kingdom : Blackwell Publishing

3. Fonseca RJ, Carlson ER, Ness GM. Oral and Maxillofacial Surgery. 2018. ed-3 (2) : 301.481. Missouri : Elsevier.

4. Ruslin, M. Hendra FN. Vojdani A, et al. The Epidemiology, Treatment, and Complication of Ameloblastoma in East Indonesia : 6 years retrospective surgery. Med Oral Patol Oral Cir Bucal. 2018. Jan 1;23 (1):e54-8.

5. Lumerman HS, Bowe RB. 2012.Atlas of Oral and Maxillofacial Histopathology. ed2; 2: 21-60.Piladelphia : Walters Kluwer Health.

6. Aramanadka C, Kamath AT, Kudva A. Recurrent Ameloblastoma: A Surgical Challenge. Hindawi : Case Reports in Dentistry. $2018: 1-6$

7. Mc Clary AC. West RB. Pollack JR.et al. Ameloblastoma: a clinical review and trends in management. Eur Arch Otorhinolaryngol. $2016: 1-13$

8. Effiom OA, Ogundana OM, Akinshipo AO, Akintoye SO. Ameloblastoma : current etiopathological concepts and management. Oral Diseases (2018) 24, 307-316

9. Masthan KMK, Anitha N, Krupaa J, et al. Ameloblastoma. J Pharm Bioallied Sci. 2015 Apr; 7(Suppl 1): S167-S170

10. Jeddy $N$, Jeyapradha $T$, Ananthalakshmi R, Jeeva $S$, Saikrishna $P$, Lakshmipathy $P$. The molecular and genetic aspects in the pathogenesis and treatment of ameloblastoma. J Dr NTR Univ Health Sci. 2013;2:157-61.

11. Koong B. 2017. Atlas of Oral and Maxillofacial Radiology. ed-1; 10: 153-178 United Kingdom : John Wiley \& Sons Ltd.

12. Sasaki R, Watanabe $Y$, Ando T, et al. Two Stage Enucleation and Deflation of a Large 
Unicystic Ameloblastoma with Mural Invasion in Mandible. Craniomaxillofac Trauma Reconstruction. 2014;7:139-142

13. Barbosa GL, Oliveira ML, Almeida SM, et al. Computed Tomography Imaging Features of Multicystic Granular Cell Ameloblastoma : A Case Report. Stomatos, Vol. 20, 39, Jul-Dec. 2014

14. Beena VT, Choudhary K, Heera R, et al. Peripheral Ameloblastoma : A Case Report and Review Literature. Hindawi Publishing Corporation. 2012;1 -4

15. Neville DW, Damm DD, Allen CM, Chi AC. 2016. Oral and Maxillofacial Pathology. ed4; 15 : 653-668. Missouri : Elsevier

16. Sadat S, Ahmed M. "Dredging Method"- $A$ Conservative Surgical Approach for the treatment of Ameloblastoma Jaw. Journal of Bangladesh College of Physicians and Surgeons. Vol 29. No.2. 2011

17. Au SW, Li KY, Choi WS, et al. Risk factors for recurrence of ameloblastoma : a longterm follow up restrospective study. Int. J. Oral Maxillofac. Surg. 2019; $7: 1-7$

18. Wright JM, Tekkesin MS. Odontogenic tumors: where are we in 2017. J Istanb Univ Fac Dent 2017;51:10-30.

19. Chichua N, Pai S, Gigineishvili E, Sharashenidze M. Management of Ameloblastoma : Desirable Treatment Approach. Caucasus Journal of Health Science and Public Health. Vol 1. 2016
20. Gunawardane S R, Attygalla A M. The Dredging Method: an Alternative Technique for Conservative Management of Ameloblastoma. A Case Report. Sri Lanka Dental Journal 2017; 47(02) 23-27. 2017

21. Malhiero P., Feio L., Costa H., Unicystic Plexiform Ameloblastoma: Case Report. Revista De Saude Amato Lusitano 2013; 32, p. 54

22. Santis GD, Cordeiro PG, Chiarini L. 2019. Atlas of Mandibular and Maxillary Reconstruction with The Fibula Flap : A step-by-step approach. ed-1;2 : 3-12. Switzerland : Springer

23. Saghravanian N, Salehinejad J, Ghazi N, Shirdel M, Razi M. A 40-year retrospective clinicopathological study of ameloblastoma in Iran. Asian Pac $J$ Cancer Prev. 2016;17:619-23

24. Rusdiana, Rusdiana, et al. "Profile of ameloblastoma from a retrospective study in Jakarta, Indonesia." Journal of Dentistry Indonesia 18.2 (2011): 27-32.

25. Wright JM, Vered M. Update from the 4th edition of the World Health organization classification of head and neck tumors: odontogenic and maxillofacial bone tumors. Head Neck Pathol 2017;11:68e77.

26. Tatapudi, Ramesh, et al. "Prevalence of ameloblastoma: A three-year retrospective study." Journal of Indian Academy of Oral Medicine and Radiology 26.2 (2014): 145 